in vivo $35: 3019-3029(2021)$

doi:10.21873/invivo.12597

Review

\title{
Peripheral Nerve Blocks for Postdural Puncture Headache: A New Solution for an Old Problem?
}

\author{
LUCA GREGORIO GIACCARI, CATERINA AURILIO, FRANCESCO COPPOLINO, MARIA CATERINA PACE, \\ MARIA BEATRICE PASSAVANTI, VINCENZO POTA and PASQUALE SANSONE \\ Department of Woman, Child and General and Specialized Surgery, \\ University of Campania "Luigi Vanvitelli", Naples, Italy
}

\begin{abstract}
Background/Aim: Postdural puncture headache $(P D P H)$ is one of the earliest recognized complications of regional anesthesia after inadvertent dural puncture. Epidural blood patch $(E B P)$ is the "gold standard" for the treatment of PDPH. Several alternatives have been suggested as peripheral nerve blocks. The aim of this systematic review was to find out the potential efficacy and safety of peripheral nerve blocks for the treatment of PDPH. Materials and Methods: The main databases were systematically searched in September 2020 for studies examining regional anesthesia and PDPH. Results: Nineteen studies were identified, including a total of 221 patients. Sphenopalatine ganglion block, greater occipital nerve block, and lesser occipital nerve block were performed. All participants reported a numeric rating scale (NRS) $<4$ after peripheral nerve blocks at 1, 24 and $48 \mathrm{~h}$. Only patients with PDPH after diagnostic lumbar puncture reported NRS $\geq 4$ after 48 h. No major adverse events were reported. Approximately, $17 \%$ of patients underwent a second or more peripheral nerve blocks. In 30 participants, EBP was required. Conclusion: To our knowledge, this is the first systematic review on the use of peripheral nerve blocks to treat PDPH. Peripheral nerve blocks can be considered as analgesic options in the management of PDPH.
\end{abstract}

The postdural puncture headache (PDPH) is one of the first recognized complications of regional anesthesia. It was

This article is freely accessible online.

Correspondence to: Pasquale Sansone, Università degli Studi della Campania "Luigi Vanvitelli”, Piazza Luigi Miraglia 2, Naples, Italy. Tel: +39 0815665180,e-mail: pasquale.sansone@unicampania.it

Key Words: Postdural puncture headache, sphenopalatine ganglion block, greater occipital nerve block, lesser occipital nerve block, review. described in 1898 by Dr. August Bier in the first patient to receive successful spinal anesthesia (1).

PDPH is one of the most common complications after accidental dural puncture (DP). The incidence of dural puncture, in the literature, ranges between $0.16 \%$ and $1.3 \%$ according to the experience of the provider (2). The development of PDPH depends on several factors, patientrelated such as young age, female sex and pregnancy, and needle-related such as design, size and direction (3-5). After DP, the incidence of PDPH ranges from $16 \%$ to $86 \%$ of cases (6).

The International Headache Society (IHS) defines PDPH as a "headache occurring within 5 days of a lumbar puncture, caused by cerebrospinal fluid (CSF) leakage through the dural puncture. It is usually accompanied by neck stiffness and/or subjective hearing symptoms. It remits spontaneously within 2 weeks or after sealing of the leak with autologous epidural lumbar patch" (7).

Management of PDPH is often challenging for anesthesiologists. For years, bed rest and aggressive hydration have been the cornerstone of the treatment of PDPH. No benefit has been demonstrated from these practices and they are not currently recommended $(3-5,8)$. A number of therapeutic agents have been suggested: analgesics, such as acetaminophen, nonsteroidal anti-inflammatory drugs (NSAIDs) or opiates, and methylxanthines, such as caffeine, are commonly used, yet the relief obtained is often inadequate, especially with severe headaches $(3-5,8)$. Other medications, such as adrenocorticotropic hormone (ACTH) and its analogues, hydrocortisone, triptans, and gabapentinoids, have been suggested to be beneficial in the management of PDPH but there is currently insufficient evidence $(3-5,8)$.

During the past several decades, the epidural blood patch (EBP) has been proposed as the "gold standard" for the treatment of PDPH (9). The exact mechanism by which the EBP relieves PDPH is still not precisely defined. The first mechanism of action is the "plug effect" when the blood 
Table I. PICO criteria for including studies.

\begin{tabular}{ll}
\hline Population & Patients of at least 18 years diagnosed with PDPH. \\
Intervetion & Regional anesthesia blocks (sphenopalatine ganglion block, greater occipital nerve block, lesser occipital nerve block). \\
Comparator & No comparator. \\
Outcomes & Pain intensity, adverse events, need for other therapeutic interventions. \\
Study type & Case report, observational study, clinical trial, randomized clinical trial. \\
Time & No time limitation.
\end{tabular}

PDPH: Postdural puncture headache; PICO: population, intervention, comparison, and outcome.

arrives at the cerebrospinal fluid (CSF) leak. The blood clotting closes the defect in the meninges and stops further CSF loss. The second is the "mass effect": the blood injected in the epidural space leads to the cephalad displacement of CSF increasing liquid pressure. Recent evidence suggests that complete and permanent relief of symptoms following a single EBP occurs in up to one third of cases. It provides complete or partial relief in around $50-80 \%$ of the cases. Possible complications of the EBP include chances of another DP, infection, and neurological sequelae such as meningitis, arachnoiditis, seizures, loss of hearing or vision, radicular pain, and neural deficits (3-5).

Several alternatives to EBP have been proposed as peripheral nerve blocks, such as sphenopalatine ganglion block (SPGB), greater occipital nerve block (GONB) and lesser occipital nerve block (LONB) (10).

As only a few randomized controlled trials (RCTs) investigating the use of these three peripheral nerve blocks have been published to our knowledge, assessment of their safety in humans relies, in part, on observational studies. In the absence of rigorous cohort studies, the best available evidence may be provided by case reports and observational studies describing efficacy in individuals suffering PDPH and receiving SPGB, GONB, or LONB, published in the peer-reviewed literature.

Whilst it is understood that randomized controlled trials are the appropriate methodology for determining efficacy and safety, case studies are often used to obtain information about the use of new techniques. In the case of PDPH, case reports of efficacy and safety events associated with SPGB, GONB and LONB should best serve as the basis to conduct RCTs.

The aim of this systematic review was to identify all relevant publications and assess their reliability regarding the potential efficacy and safety of peripheral nerve blocks for the treatment of PDPH.

\section{Materials and Methods}

Protocol and registration. We performed a systematic review based on Preferred Reporting Items for Systematic Reviews and MetaAnalyses (PRISMA) guidelines (11). This article is based on previously conducted studies and does not contain any studies with human participants or animals performed.
Eligibility criteria. The population, intervention, comparison, and outcome (PICO) criteria were applied to the research question. Patients of at least 18 years diagnosed with PDPH were considered as the population $(\mathrm{P})$; the intervention (I) was PDPH treatment using peripheral nerve blocks; the comparison (C) concept was not applicable to the research question; pain intensity, adverse events (AEs) and need for other therapeutic interventions after regional anesthesia for PDPH management were considered the outcomes $(\mathrm{O})$ for this systematic review. PICO criteria are summarized in Table I.

Literature search. We identified the articles by searching electronic databases (Embase, MEDLINE, Google Scholar and Cochrane Central Trials Register). Other relevant publications were identified from the reference lists.

We used a combination of terms such as "postdural puncture headache (PDPH)", "sphenopalatine ganglion block", "greater occipital nerve block", "lesser occipital nerve block”, "case reports", "observational study", "clinical trial”, and "randomized clinical trial”.

We applied no language restrictions in searches. The initial search was performed in September 2020 and the latest in March 2021.

The publications included in this review evaluated adult patients clinically diagnosed with PDPH who were treated with peripheral nerve blocks.

Primary outcomes. The primary outcome was the pain intensity assessed via a Numeric Rating Scale (NRS) at 0, 1, 24 and $48 \mathrm{~h}$ after treatment. Pain intensity data assessed by means other than a zero to $10 \mathrm{NRS}$ were normalized to such a scale.

Secondary outcomes. We extracted data on the following secondary outcomes: Adverse events and other therapeutic interventions (need for a second nerve block or EBP).

Selection of studies. We determined eligibility by reading the abstract of each study identified by the search. We eliminated studies that clearly did not satisfy PICO criteria and obtained full copies of the remaining studies. Two review authors (LGG and FC) read these studies independently and reached agreement by discussion.

The methodological quality of the included studies was evaluated and rated using the COSMIN checklist, which has a 4-point rating scale $(12,13)$.

Data extraction and management. Data extracted included the following: Age and sex of participants; Number of participants enrolled and completing the study; Type of operation; Regional anesthesia technique; Pain intensity for all time points at which it was measured; Severity and incidence of adverse events; Type of other therapeutic intervention. 


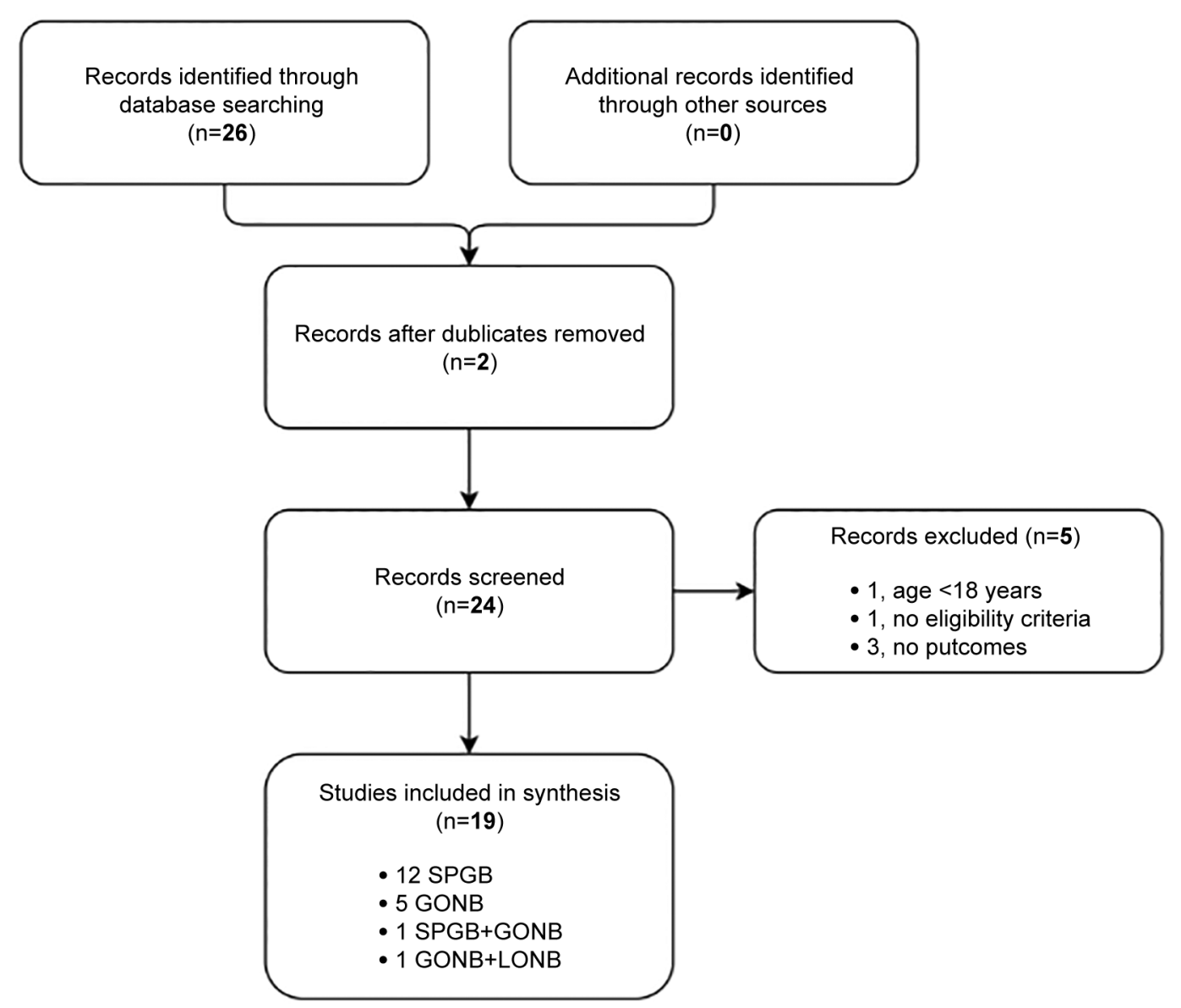

Figure 1. Flow diagram study selection process.

Statistical analysis. Data were analyzed using standard computer program (Excel, 2016). Results are reported as mean \pm standard deviation (SD). We tested the consistence of our data using Chisquare test and $95 \%$ confidence level. Comparisons were performed using Student $t$-test and the level of statistical significance was $p<0.05$.

\section{Results}

The flow diagram (Figure 1) shows the results from the literature search and the study selection process. Nineteen publications met the eligibility criteria. Table II displays the nineteen papers included in this review.

According to the COSMIN checklist, all publications included in this review showed an adequate-to-doubtful quality. Most clinical trials had a high-to-moderate risk of bias. This is due to the design of the included studies, mainly case reports and observational studies. According to the "Chauvenet's criterion", almost all data lie within one standard deviation of the mean and can be considered reliable, without the risk of outliers (Figure 2).
In the included publications, 221 patients were diagnosed with PDPH and treated with peripheral nerve blocks: 97 received SPNB, 58 received GONB, whereas the other patients received a combination of nerve blocks [42 received both SPNB and GONB in (26), 24 received both GONB and LONB in (30)]. Compared with the manuscript of Katz and Beilin (10), 7 more publications focusing exclusively on the obstetric population had been published in the meantime and they are included in this review.

Except for 33 patients [6 males (17); 6 males (20); 1 male (25); 1 male (27); 13 males (28); 1 male (29); 5 males (31)], all others included in the review were female. Niraj et al., did not report the sex of patients (31). The mean age was of $32.87 \pm 5.16$ years $(24,29,31$ did not report age of participants).

The largest publications involved 42 patients $(16,26)$, whereas the smallest consisted of single case report $(15,19$, $23,25,27)$. All analyzed studies were conducted in inpatient settings.

Patients underwent various operations; the most common surgeries were labor pain/delivery [8 studies $(16,18,19,22$, 
Table II. Publication's characteristics.

\begin{tabular}{|c|c|c|c|c|c|}
\hline Study, year & Center, No. & Design & No. & Surgery & Nerve blocks \\
\hline Cardoso JL et al. (14), 2017 & Portugal, 1 & Case Report & 1 & Sling procedure & SPGB \\
\hline Channabasappa SM et al. (15), 2017 & India, 1 & Case Report & 1 & Total abdominal hysterectomy & SPGB \\
\hline Cohen S et al. (16), 2018 & US, 1 & Observational Study & 42 & Labor pain/Delivery & SPGB \\
\hline Dubey P et al. (17), 2018 & India, 1 & Case Series & 11 & $\begin{array}{l}\text { Urological procedures or } \\
\text { cesarean section }\end{array}$ & SPGB \\
\hline Furtado et al. (18), 2018 & Portugal, 1 & Case Series & 4 & Labor pain/Delivery & SPGB \\
\hline Goncalves et al. (19), 2018 & Portugal, 1 & Case Report & 1 & Labor pain/Delivery & SPGB \\
\hline Jespersen MS et al. (20), 2020 & Denmark, 5 & Randomized Controlled Trial & 40 & $?$ & SPGB \\
\hline Kent $\mathrm{S}$ et al. (21), 2015 & US, 1 & Case Series & 3 & Diagnostic & SPGB \\
\hline Kent $\mathrm{S}$ et al. (22), 2016 & US, 1 & Case Series & 3 & Labor pain/Delivery & SPGB \\
\hline Murphy CA et al. (23), 2020 & $\mathrm{US}, 1$ & Case Report & 1 & Diagnostic & SPGB \\
\hline Puthenveettil N et al. (24), 2018 & India, 1 & Observational Study & 9 & Labor pain/Delivery & SPGB \\
\hline Singla D et al. (25), 2018 & India, 1 & Case Report & 1 & Femur reduction and fixation & SPGB \\
\hline Xavier J et al. (26), 2020 & Portugal, 1 & Observational Study & 42 & Labor pain/Delivery & $\mathrm{SPGB} \pm \mathrm{GONB}$ \\
\hline Akin Takmaz S et al. (27), 2009 & Turkey, 1 & Case Report & 1 & Inguinal hernia repair & GONB \\
\hline Akyol F et al. (28), 2015 & Turkey, 1 & Observational Study & 21 & $?$ & GONB \\
\hline Matute E et al. (29), 2008 & Spain, 1 & Case Series & 2 & Umbilical herniorrhaphy/Labor pain & GONB \\
\hline Naja et al. (30), 2009 & Lebanon, 1 & Randomized Controlled Trial & 47 & $\begin{array}{l}\text { Lower extremity fracture/ } \\
\text { Arthroscopy/Cesarean section }\end{array}$ & $\mathrm{ONB} \pm \mathrm{LONB}$ \\
\hline Niraj G et al. (31), 2014 & $\mathrm{UK}, 1$ & Observational Study & 18 & $\begin{array}{c}\text { Labor pain/Delivery or } \\
\text { non-obstetric procedures }\end{array}$ & GONB \\
\hline Türkyilmaz EU et al. (32), 2016 & Turkey, 1 & Observational Study & 16 & Labor pain/Delivery & GONB \\
\hline
\end{tabular}

SPGB: Sphenopalatine ganglion block; GONB: greater occipital nerve block; LONB: lesser occipital nerve block; US: United States; UK: United Kingdom.

$24,26,29,31,32)]$, followed by gynecological [3 studies $(15,17,30)]$, abdominal [2 studies $(27,29)]$, diagnostic [2 studies $(21,23)]$, urological $[2$ studies $(14,23)]$, and orthopedic procedures [2 studies $(25,30)]$. Two studies $(20$, 28) did not report the intervention.

Concerning anesthesia technique, peridural anesthesia was performed 10 times (14, 16, 18-21, 24, 26, 29, 31); subarachnoid anesthesia was reported in ten studies $(17,20$, 25-32); combined spinal-epidural (CSE) technique was performed in three studies $(15,18,26)$; finally, in two studies $(21,23)$ patients underwent diagnostic lumbar puncture (LP).

Not all publications reported the type of needle used to administer anesthesia. Where data are available, peridural was administered using 16-gauge or 18-gauge Tuohy needles; 25 gauge or 27-gauge Quincke and 27-gauge Whitacre needles were used for spinal anesthesia. In the study by Türkyilmaz et al., spinal blocks were performed using 26-gauge needles with an atraumatic bevel (Atraucan ${ }^{\circledR}$, B-Braun, Melsunger, Germany) (32). PDPH appeared between the first (18, 22, 23, $27,29)$ and seventh (14) day after the anesthetic procedure.

In some publications, patients referred the associated symptoms of nausea $(14,16,17,19,23,30)$, vomiting $(14$, $17,30)$, photophobia $(16,17,30)$, phonophobia $(16,30)$, dizziness $(19,30)$, blurry vision $(21,30)$, loss of appetite (30), and ataxia (30).

Conservative treatment was administered and consisted of bed rest and postural measures, oral and intravenous hydration, caffeine and multimodal analgesia (acetaminophen, NSAIDs and opioids). Three studies $(16,17,22)$ did not report conservative management.

Peripheral nerve blocks. Sphenopalatine ganglion block was performed using cotton-tip applicators dipped into local anesthetic: $0.5 \%$ levobupivacaine (14), $2 \%$ lidocaine $(21,22,24), 4 \%$ lidocaine $(16,23), 0.75 \%$ ropivacaine $(18$, $19)$, and a mixture of $4 \%$ lidocaine and $0.5 \%$ ropivacaine (20). In two studies $(15,25), 0.75 \%$ ropivacaine was respectively injected using a spinal needle and an epidural catheter. Xavier et al. performed SPGB with $1 \%$ ropivacaine both using cotton-tip applicators or an epidural catheter (26). Dubey et al. used intranasal lidocaine spray (17).

Greater occipital nerve block consisted of injecting local anesthetic lateral to external occipital protuberance. Akin Takmaz et al. (27) used $0.5 \%$ ropivacaine, Akyol et al. (28) $0.25 \%$ levobupivacaine, Matute et al. $0.5 \%$ bupivacaine and triamcinolone, Naja et al. (30) 1\% lidocaine, Niraj et al. (31) $1 \%$ lidocaine and dexamethasone, Türkyilmaz et al. (32) $0.25 \%$ levobupivacaine and dexamethasone, and Xavier et al. (26) $1 \%$ ropivacaine.

In Naja et al. (30), lesser occipital nerve block was performed injecting $1 \%$ lidocaine at the superior third of the posterior limit of the sternocleidomastoid muscle.

Table III summarizes the techniques used. 

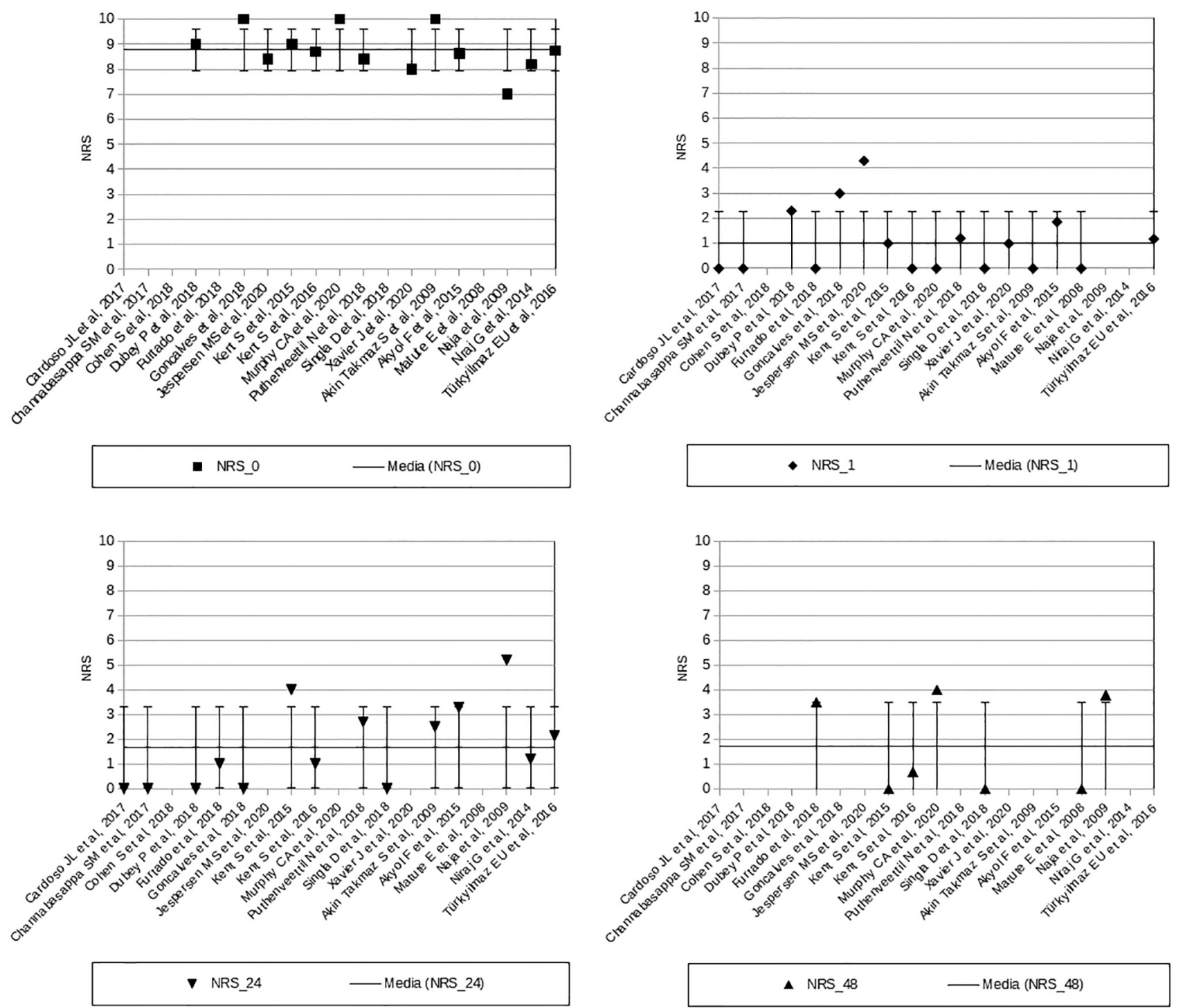

Figure 2. Data distribution (Chauvenet's criterion).

Pain intensity. Different investigators recorded pain intensity on different scales and at different intervals. We normalized all NRS to a zero to 10 range (Table IV). The majority of authors reported pain intensity before performing SPGB, GONB or LONB and 1, 24 and $48 \mathrm{~h}$ after treatment. Pain intensity before the procedure was reported in 13 publications, which involved 170 patients with PDPH. All participants reported NRS $\geq 8$, except in Akyol et al. (28), (NRS 6.26) and Naja et al. (30) (NRS 7).

After $1 \mathrm{~h}$, NRS was lower than 4 in all publications except for Jespersen et al. (20) NRS $\geq 4$ was only reported in Kent et al. (21) and Naja et al. (30) at $24 \mathrm{~h}$ after nerve block, and in Murphy et al. (23) at $48 \mathrm{~h}$.
Pain intensity before the procedure was $8.59 \pm 1.06$. NRS was $1.05 \pm 0.28$ after $1 \mathrm{~h}, 1.78 \pm 1.83$ after $24 \mathrm{~h}$, and $1.71 \pm 1.79$ after 48 h. Cohen et al. (16) did not report pain evaluation. Approximately, $71.4 \%$ of patients experienced headache relief $1 \mathrm{~h}$ after SPGB after the EBP treatment. After 24 and 48 h, SPGB was effective in $85.7 \%$ and $92.9 \%$ of cases, respectively.

We made the hypothesis that these results can be well described by a single number, determining the weighted mean of the measurements. We performed Chi-square test using $95 \%$ confidence level for available data before $\left(\mathrm{x}^{2} / v=6.57 / 5 \approx 1.31 ; \alpha=0.25\right)$, at $1 \mathrm{~h} \quad\left(\mathrm{x}^{2} / v=0.44 / 4 \approx 0.11\right.$; $\alpha=0.98), \quad 24 \mathrm{~h} \quad\left(\mathrm{x}^{2} / v=6.06 / 6 \approx 1.01 ; \alpha=0.42\right)$ and $48 \mathrm{~h}$ 
Table III. Peripheral nerve blocks techniques.

Peripheral nerve blocks techniques

Cardoso JL et al. (14), 2017

Channabasappa SM et al. (15), 2017

Cohen S et al. (16), 2018

Dubey P et al. (17), 2018

Furtado et al. (18), 2018

Goncalves et al. (19), 2018

Jespersen MS et al. (20), 2020

Kent $\mathrm{S}$ et al. (21), 2015

Kent $\mathrm{S}$ et al. (22), 2016

Murphy CA et al. (23), 2020

Puthenveettil N et al. (24), 2018

Singla D et al. (25), 2018

Xavier J et al. (26), 2020

Akin Takmaz S et al. (27), 2009

Akyol F et al. (28), 2015

Matute E et al. (29), 2008

Naja et al. (30), 2009

Niraj G et al. (31), 2014

Türkyilmaz EU et al. (32), 2016
Cotton-tip applicators dipped into $0.5 \%$ levobupivacaine

Intranasal $0.5 \%$ ropivacaine injection (spinal needle)

Cotton-tip applicators dipped into $4 \%$ lidocaine Intranasal lidocaine spray

Cotton-tip applicators dipped into $0.75 \%$ ropivacaine

Cotton-tip applicators dipped into $0.75 \%$ ropivacaine

Cotton-tip applicators dipped into $4 \%$ lidocaine and $0.5 \%$ ropivacaine

Cotton-tip applicators dipped into $2 \%$ lidocaine

Cotton-tip applicators dipped into $2 \%$ lidocaine

Cotton-tip applicators dipped into $4 \%$ lidocaine

Cotton-tip applicators dipped into $2 \%$ lidocaine

Intranasal $0.5 \%$ ropivacaine injection (epidural catheter)

SPGB: Intranasal $1 \%$ ropivacaine injection (epidural catheter) or cotton-tip applicators dipped into $1 \%$ ropivacaine

GONB: $1 \%$ ropivacaine injection lateral to external occipital protuberance (L)

$0.5 \%$ ropivacaine injection lateral to external occipital protuberance (L)

$0.25 \%$ levobupivacaine injection lateral to external occipital protuberance (US)

$0.5 \%$ bupivacaine and triamcinolone injection lateral to external occipital protuberance (?)

GONB: $1 \%$ lidocaine injection lateral to external occipital protuberance (L)

LONB: $1 \%$ lidocaine at the superior third of the posterior limit of the sternocleidomastoid muscle (L) $1 \%$ lidocaine and dexamethasone injection lateral to external occipital protuberance (L)

$0.25 \%$ levobupivacaine and dexamethasone injection lateral to external occipital protuberance $(\mathrm{L})$

SPGB: Sphenopalatine ganglion block; GONB: greater occipital nerve block; LONB: lesser occipital nerve block; L: Landmarks technique; US: ultrasound technique.

$\left(\mathrm{x}^{2} / v=0.57 / 1 \approx 0.57 ; \alpha=0.45\right)$ after peripheral nerve blocks. We have therefore no good reason to reject the hypothesis and conclude that the measurements are consistent with each other.

We performed Student $t$-test between NRS before treatment and after $1 \mathrm{~h}(p<0.05), 24 \mathrm{~h}(p<0.05)$, and $48 \mathrm{~h}$ $(p<0.05)$. No statistical difference was found between NRS after 1 and $24 \mathrm{~h}(p=0.37)$, and after 24 and $48 \mathrm{~h}(p=0.52)$.

Adverse events (AEs). An adverse event is defined as any undesirable experience associated with the use of a medical product in a patient. No AE was reported after the execution of SPGB, GONB or LONB, except in Jespersen MS et al. (2020) and Murphy CA et al. (2020). In the first study, AEs were recorded in 10 patients: one patient reported severe nasal discomfort and nausea during the insertion, and five patients reported light pain or discomfort during the insertion. Throat discomfort, light left ear pain during insertion and tingling sensation in the left cheek during insertion were also reported after receiving the block. In Murphy CA et al. (2020), the patient described an unpleasant taste after dropping the lidocaine into nostril.

Other therapeutic interventions. A total of 38 patients needed to receive a second or more nerve blocks, SPGB, GONB or LONB, and 30 patients an EBP.
In five patients, the procedure had to be repeated after 1 h (17). A second SPGB was performed in 2 patients after 24 $\mathrm{h}$ with relief in the next hour (18); two other patients received EBP. In Jespersen et al. (20) from $1 \mathrm{~h}$ to 7 days after the block, 13 patients received a rescue block and 10 received an EBP.

Xavier et al. (26) reported 2 courses in 15 patients; among these, nine patients required EBP due to treatment failure with peripheral nerve block. Kent et al. (21) reported EBP after $12 \mathrm{~h}$ with complete resolution of headache.

A total of 3 patients treated with $\operatorname{GONB}(27,32)$ received a second nerve block with pain resolution. Türkyilmaz et al. (32) reported a patient's NRS did not change two hours after primary GONB and an EBP was performed. Following occipital block (30), the headache was completely relieved in $68.4 \%$ of patients after one to two injections; the remaining $31.6 \%$ of patients experienced relief only after the third or fourth injection. In Niraj et al. (31), six patients reported partial resolution of the symptoms after GONB and all received EBP.

\section{Discussion}

In this review, several publications describe the use of peripheral nerve blocks as a treatment for PDPH, most with 
Table IV. Pain intensity (mean $\pm S D)$ evaluated at 0, 1, 24 and 48 hours.

\begin{tabular}{|c|c|c|c|c|}
\hline & NRS 0 & NRS $1 \mathrm{~h}$ & NRS $24 \mathrm{~h}$ & NRS $48 \mathrm{~h}$ \\
\hline Cardoso JL et al. (14), 2017 & - & $0 \pm 0$ & $0 \pm 0$ & - \\
\hline Channabasappa SM et al. (15), 2017 & - & $0 \pm 0$ & $0 \pm 0$ & - \\
\hline Cohen S et al. (16), 2018 & - & - & - & - \\
\hline Dubey P et al. (17), 2018 & $9.0 \pm \mathrm{na}$ & $2.3 \pm$ na & $0 \pm$ na & - \\
\hline Furtado et al. (18), 2018 & - & $0 \pm 0$ & $1.0 \pm 1.73$ & $3.5 \pm 3.57$ \\
\hline Goncalves et al. (19), 2018 & $10 \pm 0$ & $3.0 \pm 0$ & $0 \pm 0$ & - \\
\hline Jespersen MS et al. (20), 2020 & $8.4 \pm$ na & $4.3 \pm$ na & - & - \\
\hline Kent $\mathrm{S}$ et al. (21), 2015 & $9.0 \pm 0$ & $2.0 \pm 1.41$ & $5.6 \pm 1.69$ & $0 \pm 0$ \\
\hline Kent S et al. (22), 2016 & $8.7 \pm 0.57$ & $0 \pm 0$ & $1.0 \pm 1.41$ & $0.7 \pm 0.94$ \\
\hline Murphy CA et al. (23), 2020 & $10 \pm 0$ & $0 \pm 0$ & - & $4.0 \pm 0$ \\
\hline Puthenveettil N et al. (24), 2018 & $8.4 \pm 0.7$ & $1.2 \pm 2.4$ & $2.7 \pm 0.5$ & - \\
\hline Singla D et al. (25), 2018 & - & $0 \pm 0$ & $0 \pm 0$ & $0 \pm 0$ \\
\hline Xavier J et al. (26), 2020 & $8.0 \pm 1.5$ & $1.0 \pm 1.5$ & - & - \\
\hline Akin Takmaz S et al. (27), 2009 & $10 \pm 0$ & $0 \pm 0$ & $2.5 \pm 0$ & - \\
\hline Akyol F et al. (28), 2015 & $6.26 \pm 0.84$ & $1.86 \pm 0.59$ & $3.28 \pm 0.9$ & - \\
\hline Matute E et al. (29), 2008 & - & $0 \pm 0$ & - & $0 \pm 0$ \\
\hline Naja et al. (30), 2009 & $7 \pm$ na & - & $5.2 \pm \mathrm{na}$ & $3.8 \pm \mathrm{na}$ \\
\hline Niraj G et al. (31), 2014 & $8.2 \pm 1.25$ & - & $1.57 \pm 0.82$ & - \\
\hline Türkyilmaz EU et al. (32), 2016 & $8.75 \pm 0.9$ & $1.18 \pm 1.97$ & $2.13 \pm 1.58$ & - \\
\hline TOTAL & $8.59 \pm 1.06$ & $1.05 \pm 1.28$ & $1.78 \pm 1.83$ & $1.71 \pm 1.79$ \\
\hline$p$-Value & & $<0.05$ & $<0.05$ & $<0.05$ \\
\hline
\end{tabular}

NRS: Numeric rating scale; na: not available.

a sphenopalatine ganglion block, greater occipital nerve block, and lesser occipital nerve block.

The sphenopalatine ganglion (SPG) is the largest of the four parasympathetic ganglions of the head. It is located in the pterygopalatine fossa between the middle nasal concha posteriorly and the pterygoid canal anteriorly (33). SPG receives sensory, sympathetic and parasympathetic fibers. It activates cerebral vasodilatation and increases cerebral blood flow. SPG activation may result in the release of several peptides increasing plasma protein extravasation with neurogenic inflammation and activation of trigeminal nociceptors contributing to pain and triggering headache (34).

Since Dr. Greenfield Sluder described the SPG as a pain originator and transmitter in $1908(35,36)$, it has been blocked using different techniques. SPG may absorb local anesthetic via the middle turbinate and lateral nasal mucosa from a cotton-tipped applicator, the so-called "intranasal approach“ (33). SPGB has been reported in the management of cluster headache (37), migraine (38), trigeminal neuralgia (39), herpes zoster involving the ophthalmic nerve (40), paroxysmal hemicrania (41), and neck cancer pain (42), atypical facial pain (43), complex regional pain syndrome (CRPS) (44), temporomandibular disorder (45), nasal contact point headache (46), and vasomotor rhinitis (47).

The greater occipital nerve (GON) is the sensory branch of the posterior ramus of the $\mathrm{C} 2$ spinal nerve. It innervates the skin of the occipital region up to the vertex, together with the lesser occipital nerve (48). The GON is the main sensory nerve of the occipital area and is involved in various pain syndromes such as occipital neuralgia (49), cervicogenic headaches (50), and migraines (51). The GONB consists of injection of local anesthetic medial to the occipital artery at the level of the superior nuchal line (SNL), i.e., one-third of the distance between the external occipital protuberance and the mastoid process (52).

The lesser occipital nerve (LON) is the superficial branch of the cervical plexus and it is formed by fibers of ventral rami of $\mathrm{C} 2$ and $\mathrm{C} 3$. It is responsible for the innervation of the lateral part of the occiput. The nerve is located at the lateral third of a hypothetical line between the mastoid process and occipital protuberance (48). The LONB is usually performed together with the GONB to treat headache of the lateral portion of the occipital region.

In this analysis, the intranasal approach was commonly performed for SPGB. The advantage of this approach is that it may be performed in an ambulatory setting. Dubey et al. (17) hypothesized that lidocaine nasal spray should also be effective in achieving SPG anesthesia. The classical landmark technique was used for GONB, except in Akyol et al. (28), and LONB. However, the ultrasound guided technique is more target specific and it should be preferred (53). Lidocaine, levobupivacaine, bupivacaine, or ropivacaine were the local anesthetics of choice.

Pain intensity. Pain intensity on the NRS was $<4$ in all participants after peripheral nerve blocks at 1, 24 and $48 \mathrm{~h}$, with the exception of the results reported by Jespersen et al. 
(2020) at $1 \mathrm{~h}$, Kent et al. (21) and Naja et al. (30) at $24 \mathrm{~h}$, and Murphy et al. (23) at $48 \mathrm{~h}$.

We considered NRS $<4$ as optimal cut-off point between mild and moderate pain. This cut-off was identified as the tolerable pain threshold (54). Jespersen et al. (20) and Naja et al. (30) showed NRS lower than 4 in the subsequent surveillance intervals.

Kent et al. (21) and Murphy et al. (23) reported the first case series in which SPGB was offered to patients who have received diagnostic LPs and then presented to the emergency department (ED) with PDPH. Postdural puncture headache occurs in $10 \%$ to $40 \%$ of subjects after LP (55). The more serious symptoms could depend on the greater CSF leakage, according with Bier's hypothesis that continued CSF leakage through the lumbar puncture site could be an important contributing factor for PDPH $(56,57)$.

Safety. No AEs were reported after the execution of SPGB or GONB, except in Jespersen et al. (20) and Murphy et al. (23). Discomfort related to the insertion of cotton-tip applicators intranasally was reported.

The most common AEs related to SPGB are: epistaxis secondary to aggressive placement of a cotton-tipped applicator into the nasal passage; local or retro-orbital hematoma can result from puncturing the venous plexus overlying the pterygopalatine fossa or maxillary artery, including branches; infection may occur without aseptic technique (33).

The most frequent side effects of GONB include pain at the injection site and numbness. Lightheadedness and syncope may also occur, as well as local hematoma, local infection, and nausea. Skin atrophy, hyperpigmentation or hypopigmentation of the skin, and local alopecia have also been reported when GON block is used in conjunction with steroids (44).

However, these peripheral nerve blocks seem to be safe and well-tolerated compared to other treatments and their side effects.

Compared to these relatively safe techniques, EBP includes chances of another possible DP, infection, and neurological sequelae such as meningitis, arachnoiditis, seizures, loss of hearing or vision, radicular pain, and neural deficits (3-5). Furthermore, a higher prevalence of low back pain (LBP) has recently been highlighted (58). Peripheral nerve blocks seem to improve the care provided to patients and further reduce levels of perceived pain in the postoperative period (59).

Other therapeutic interventions. A total of 38 patients $(17 \%$ of total: 19 SPGB, 4 GONB, 15 SPGB + GONB) underwent a second peripheral nerve block due to uncontrolled pain. Among these, sixteen patients reported complete resolution of symptoms after the second course.
In 30 participants (13\% of total), epidural blood patch was required. Two patients required a second EBP (18), while a second GONB was necessary after unsuccessful EBP in Niraj et al. (31). The remaining patients showed complete pain resolution following the rescue procedure.

All cases of PDPH requiring EBP followed epidural block or CSE. Dural puncture with a Tuohy needle is the most likely culprit of PDPH with severe symptoms requiring $\mathrm{EBP}$, both as first-line treatment or as rescue therapy after a less invasive treatment has failed (60). None of the cases of PDPH following spinal anesthesia required EBP for satisfactory treatment, expect in Türkyilmaz et al. (32).

EBP might be avoidable in cases of PDPH after subarachnoid block, in favor of less invasive techniques such as SPGB, GONB or LONB, in addition to standard conservative treatment. On the other hand, PDPH may be successfully treated with peripheral nerve blocks, but occasionally EBP could be required.

Limitations. This review has some limitations. First, a major limitation is the use of case series and observational studies in this review. Due to the greater potential for bias, they are often excluded from systematic reviews of treatments. In a typical systematic review of a rapidly developing technology, that are peripheral nerve blocks for the treatment of PDPH, case series and observational studies contribute substantially to the available evidence, and their results supplement the limited evidence available from other studies. Second, the lack of RCT assessing the efficacy of peripheral nerve blocks in the management of PDPH is a major limitation to this work. PDPH usually improves over time and so it is difficult to establish whether the nerve block itself relieved symptoms or whether this improvement would have occurred without intervention.

Third, patients presenting for peripheral nerve blocks were both male and female of varying age, some were obstetric while others were post-surgical or presented with PDPH following diagnostic lumbar puncture. The needles used were of different size and design. A variety of the other therapies were used in addition to peripheral nerve blocks. The length of time for which patients were followed-up also varied. The technique of SPGB and GONB varied between reports. Consequently, there is great heterogeneity in patients and techniques included in this review. Finally, other potential biases should be taken into account, such as: biases inherent in this study design; over representation of specialist centers with better results than routine clinical practice; publication bias; possible multiple publication of results from the same patients in several series (61).

\section{Conclusion}

This is the first systematic review on the use of peripheral nerve blocks to treat PDPH. Peripheral nerve blocks can be considered as analgesic options in the management of PDPH, 
as not all cases of PDPH require EBP for successful treatment. The purpose of peripheral nerve blocks is to relieve the distressing headache experienced by a patient who had a dural puncture.

Treatment of PDPH with peripheral nerve blocks is a minimally invasive, easy and effective method, which could be offered to patients when conservative management is ineffective. Even after a partially successful block, SPGB, GONB or LONB could be repeated. Nerve blocks could also be offered to patients who did not receive complete pain relief after an EBP and are not willing to undergo a repeated EBP. The injection does not address the ongoing CSF leak, therefore other supportive measures like bed rest, hydration and analgesics should be continued.

Given the nature of the publications available to date, we cannot provide any recommendations on the use of peripheral nerve blocks in the treatment of PDPH. Welldesigned controlled studies are needed to assess the role of these peripheral nerve blocks in the treatment of PDPH.

\section{Conflicts of Interest}

The Authors declare that they have no competing interests in relation to this study.

\section{Authors' Contributions}

LGG helped design the study, conduct the study, analyse the data, and write the manuscript; CA helped design the study and analyse the data; FC helped design the study and analyse the data; MCP helped design the study and analyse the data; MBP helped design the study and analyse the data; VP helped design the study and analyse the data; PS helped design the study, conduct the study and analyse the data. All Authors have read and approved the manuscript.

\section{References}

1 Bier A: Experiments regarding the cocainization on the spinal cord. Zeitschrift fur Chirurgie 51: 361-368, 1899.

2 Reynolds F: Dural puncture and headache: avoid the first but treat the second. Brit Med J 306(882): 874-876, 1993.

3 Kwak KH: Postdural puncture headache. Korean J Anesthesiol 70(2): 136-143, 2017. PMID: 28367283. DOI: 10.4097/kjae. 2017.70.2.136

4 Patel R, Urits I, Orhurhu V, Orhurhu MS, Peck J, Ohuabunwa E, Sikorski A, Mehrabani A, Manchikanti L, Kaye AD, Kaye RJ, Helmstetter JA and Viswanath O: A comprehensive update on the treatment and management of postdural puncture headache. Curr Pain Headache Rep 24(6): 24, 2020. PMID: 32323013. DOI: $10.1007 / \mathrm{s} 11916-020-00860-0$

5 Ghaleb A: Postdural puncture headache. Anesthesiol Res Pract 2010: 102967, 2010. PMID: 20814596. DOI: 10.1155/2010/102967

6 Liu S, Carpenter RL and Neal JM: Epidural anesthesia and analgesia. Their role in postoperative outcome. Anesthesiology 82(6): 1474-1506, 1995. PMID: 7793661. DOI: 10.1097/ 00000542-199506000-00019
7 International Headache Society (IHS) Classification ICHD 3. Available at: https://ichd-3.org/7-headache-attributed-to-nonvascular-intracranial-disorder/7-2-headache-attributed-to-lowcerebrospinal-fluid-pressure/7-2-1-post-dural-puncture-headache/ [Last acceded on September 2, 2020]

8 Russell R, Laxton C, Lucas DN, Niewiarowski J, Scrutton M and Stocks G: Treatment of obstetric post-dural puncture headache. Part 1: conservative and pharmacological management. Int J Obstet Anesth 38: 93-103, 2019. PMID: 30711240. DOI: 10.1016/j.ijoa.2018.12.006

9 Russell R, Laxton C, Lucas DN, Niewiarowski J, Scrutton M and Stocks G: Treatment of obstetric post-dural puncture headache. Part 2: epidural blood patch. Int J Obstet Anesth 38: 104-118, 2019. PMID: 30711239. DOI: 10.1016/j.ijoa.2018.12.005

10 Katz D and Beilin Y: Review of the alternatives to epidural blood patch for treatment of postdural puncture headache in the parturient. Anesth Analg 124(4): 1219-1228, 2017. PMID: 28079587. DOI: $10.1213 /$ ANE.0000000000001840

11 Moher D, Liberati A, Tetzlaff J, Altman DG and PRISMA Group: Preferred reporting items for systematic reviews and meta-analyses: the PRISMA statement. J Clin Epidemiol 62(10): 1006-1012, 2009. PMID: 19631508. DOI: 10.1016/j.jclinepi. 2009.06.005

12 Terwee CB, Mokkink LB, Knol DL, Ostelo RW, Bouter LM and de Vet HC: Rating the methodological quality in systematic reviews of studies on measurement properties: a scoring system for the COSMIN checklist. Qual Life Res 21(4): 651-657, 2012. PMID: 21732199. DOI: 10.1007/s11136-011-9960-1

13 Mokkink LB, Terwee CB, Patrick DL, Alonso J, Stratford PW, Knol DL, Bouter LM and de Vet HC: The COSMIN checklist for assessing the methodological quality of studies on measurement properties of health status measurement instruments: an international Delphi study. Qual Life Res 19(4): 539-549, 2010. PMID: 20169472. DOI: 10.1007/s11136-0109606-8

14 Cardoso JM, Sá M, Graça R, Reis H, Almeida L, Pinheiro C and Machado D: [Sphenopalatine ganglion block for postdural puncture headache in ambulatory setting]. Rev Bras Anestesiol 67(3): 311-313, 2017. PMID: 28364968. DOI: 10.1016/j.bjan. 2017.02 .003

15 Channabasappa SM, Manjunath S, Bommalingappa B, Ramachandra S and Banuprakash S: Transnasal sphenopalatine ganglion block for the treatment of postdural puncture headache following spinal anesthesia. Saudi J Anaesth 11(3): 362-363, 2017. PMID: 28757848. DOI: 10.4103/sja.SJA_59_17

16 Cohen S, Levin D, Mellender S, Zhao R, Patel P, Grubb W and Kiss G: Topical sphenopalatine ganglion block compared with epidural blood patch for postdural puncture headache management in postpartum patients: a retrospective review. Reg Anesth Pain Med 43(8): 880-884, 2018. PMID: 30063655. DOI: 10.1097/AAP.0000000000000840

17 Dubey $\mathrm{P}$ and Dubey PK: Intranasal lignocaine spray for sphenopalatine ganglion block for postdural puncture headache. Saudi J Anaesth 12(2): 364-365, 2018. PMID: 29628865. DOI: 10.4103/sja.SJA_680_17

18 Furtado I, Lima IF and Pedro S: [Ropivacaine use in transnasal sphenopalatine ganglion block for post dural puncture headache in obstetric patients - case series]. Braz J Anesthesiol 68(4): 421-424, 2018. PMID: 29402441. DOI: 10.1016/j.bjan.2017. 11.007 
19 Gonçalves LM, Godinho PM, Durán FJ and Valente EC Sphenopalatine ganglion block by transnasal approach in postdural puncture headache. J Clin Anesth 48: 50, 2018. PMID: 29751211. DOI: 10.1016/j.jclinane.2018.05.006

20 Jespersen MS, Jaeger P, Ægidius KL, Fabritius ML, Duch P, Rye I, Afshari A and Meyhoff CS: Sphenopalatine ganglion block for the treatment of postdural puncture headache: a randomised, blinded, clinical trial. Br J Anaesth 124(6): 739-747, 2020. PMID: 32303377. DOI: 10.1016/j.bja.2020.02.025

21 Kent S and Mehaffey G: Transnasal sphenopalatine ganglion block for the treatment of postdural puncture headache in the ED. Am J Emerg Med 33(11): 1714.e1-1714.e2, 2015. PMID: 25819208. DOI: 10.1016/j.ajem.2015.03.024

22 Kent S and Mehaffey G: Transnasal sphenopalatine ganglion block for the treatment of postdural puncture headache in obstetric patients. J Clin Anesth 34: 194-196, 2016. PMID: 27687372. DOI: 10.1016/j.jclinane.2016.04.009

23 Murphy CA, McBride D and Sharma S: Sphenopalatine ganglion block for postdural puncture headache. Pain Med 21(10): 26152616, 2020. PMID: 32049339. DOI: 10.1093/pm/pnz351

24 Puthenveettil N, Rajan S, Mohan A, Paul J and Kumar L: Sphenopalatine ganglion block for treatment of post-dural puncture headache in obstetric patients: An observational study. Indian J Anaesth 62(12): 972-977, 2018. PMID: 30636799. DOI: 10.4103/ija.IJA_443_18

25 Singla D and Mangla M: Sphenopalatine ganglion block: A newer modality for management of postdural puncture headache. J Anaesthesiol Clin Pharmacol 34(4): 567-568, 2018. PMID: 30774251. DOI: 10.4103/joacp.JOACP_64_17

26 Xavier J, Pinho S, Silva J, Nunes CS, Cabido H, Fortuna R, Araújo R, Lemos $\mathrm{P}$ and Machado $\mathrm{H}$ : Postdural puncture headache in the obstetric population: a new approach? Reg Anesth Pain Med 45(5): 373-376, 2020. PMID: 32094239. DOI: 10.1136/rapm-2019-101053

27 Akin Takmaz S, Unal Kantekin C, Kaymak C and Başar H: Treatment of post-dural puncture headache with bilateral greater occipital nerve block. Headache 50(5): 869-872, 2010. PMID: 20353435. DOI: $10.1111 / \mathrm{j} .1526-4610.2010 .01656 . x$

28 Akyol F, Binici O, Kuyrukluyildiz U and Karabakan G: Ultrasound-guided bilateral greater occipital nerve block for the treatment of post-dural puncture headache. Pak J Med Sci 31(1): 111-115, 2015. PMID: 25878625. DOI: 10.12669/pjms.311.5759

29 Matute E, Bonilla S, Gironés A and Planas A: Bilateral greater occipital nerve block for post-dural puncture headache. Anaesthesia 63(5): 557-558, 2008. PMID: 18412667. DOI: 10.1111/j.1365-2044.2008.05531.x

30 Naja Z, Al-Tannir M, El-Rajab M, Ziade F and Baraka A: Nerve stimulator-guided occipital nerve blockade for postdural puncture headache. Pain Pract 9(1): 51-58, 2009. PMID: 19019052. DOI: 10.1111/j.1533-2500.2008.00238.x

31 Niraj G, Kelkar A and Girotra V: Greater occipital nerve block for postdural puncture headache (PDPH): a prospective audit of a modified guideline for the management of PDPH and review of the literature. J Clin Anesth 26(7): 539-544, 2014. PMID: 25441250. DOI: $10.1016 /$ j.jclinane.2014.03.006

32 Uyar Türkyilmaz E, Camgöz Eryilmaz N, Aydin Güzey N and Moraloğlu Ö: Bilateral greater occipital nerve block for treatment of post-dural puncture headache after caesarean operations. Braz J Anesthesiol 66(5): 445-450, 2016. PMID: 27591456. DOI: 10.1016/j.bjane.2015.03.004
33 Skulpoonkitti B and Day M: Sphenopalatine ganglion blocks. In: Essentials of interventional techniques in managing chronic pain. Manchikanti L, Kaye A, Falco F, Hirsch J (eds.). Springer, Cham, Switzerland, 2018.

34 Robbins MS, Robertson CE, Kaplan E, Ailani J, Charleston L 4th, Kuruvilla D, Blumenfeld A, Berliner R, Rosen NL, Duarte R, Vidwan J, Halker RB, Gill N and Ashkenazi A: The sphenopalatine ganglion: Anatomy, pathophysiology, and therapeutic targeting in headache. Headache 56(2): 240-258, 2016. PMID: 26615983. DOI: 10.1111/head.12729

35 Sluder G: The role of the sphenopalatine ganglion in nasal headache. NY State J Med 27: 8-13, 1908.

36 Ruskin S: Contributions to the study of the sphenopalatine ganglion. Laryngoscope 36: 87-108, 1925.

37 Rosso C, Felisati G, Bulfamante A and Pipolo C: Cluster headache: crosspoint between otologists and neurologiststreatment of the sphenopalatine ganglion and systematic review. Neurol Sci 40(Suppl 1): 137-146, 2019. PMID: 30877613. DOI: 10.1007/s10072-019-03796-5

38 Binfalah M, Alghawi E, Shosha E, Alhilly A and Bakhiet M: Sphenopalatine ganglion block for the treatment of acute migraine headache. Pain Res Treat 2018: 2516953, 2018. PMID: 29862074. DOI: $10.1155 / 2018 / 2516953$

39 Lima MH, Campos MJ, Valentim A, Paulo L, Rego S and Semedo E: Intranasal self-administration of local anesthetic (ropivacaine) for sphenopalatine ganglion block, for treatment of second trigeminal branch neuralgia secondary to maxillary sinus curettage: A case report. Rev Esp Anestesiol Reanim (Engl Ed) 66(8): 447450, 2019. PMID: 31395405. DOI: 10.1016/j.redar.2019.02.007

40 Prasanna A and Murthy PS: Combined stellate ganglion and sphenopalatine ganglion block in acute herpes infection. Clin J Pain 9(2): 135-137, 1993. PMID: 8358137. DOI: 10.1097/ 00002508-199306000-00009

41 Morelli N, Mancuso M, Felisati G, Lozza P, Maccari A, Cafforio G, Gori S, Murri L and Guidetti D: Does sphenopalatine endoscopic ganglion block have an effect in paroxysmal hemicrania? A case report. Cephalalgia 30(3): 365-367, 2010. PMID: 19438918. DOI: 10.1111/j.1468-2982.2009.01882.x

42 Sanghavi PR, Shah BC and Joshi GM: Home-based application of sphenopalatine ganglion block for head and neck cancer pain management. Indian J Palliat Care 23(3): 282-286, 2017. PMID: 28827931. DOI: 10.4103/IJPC.IJPC_39_17

43 Klein RN, Burk DT and Chase PF: Anatomically and physiologically based guidelines for use of the sphenopalatine ganglion block versus the stellate ganglion block to reduce atypical facial pain. Cranio 19(1): 48-55, 2001. PMID: 11842841. DOI: 10.1080/08869634.2001.11746151

44 Quevedo JP, Purgavie K, Platt H and Strax TE: Complex regional pain syndrome involving the lower extremity: a report of 2 cases of sphenopalatine block as a treatment option. Arch Phys Med Rehabil 86(2): 335-337, 2005. PMID: 15706564. DOI: $10.1016 /$ j.apmr.2004.04.033

45 Peterson JN, Schames J, Schames $M$ and King E: Sphenopalatine ganglion block: a safe and easy method for the management of orofacial pain. Cranio 13(3): 177-181, 1995. PMID: 8949858. DOI: 10.1080/08869634.1995.11678065

46 Lee SH, Kim Y and Lim TY: Efficacy of sphenopalatine ganglion block in nasal mucosal headache presenting as facial pain. Cranio 38(2): 128-130, 2020. PMID: 29882504. DOI: $10.1080 / 08869634.2018 .1475859$ 
47 Prasanna A and Murthy PS: Vasomotor rhinitis and sphenopalatine ganglion block. J Pain Symptom Manage 13(6): 332-338, 1997. PMID: 9204653. DOI: 10.1016/s0885-3924(97)00008-0

48 Uygunoglu U and Siva A: Greater occipital nerve and lesser occipital nerve blocks. In: Peripheral Interventional Management in Headache. Özge A, Uludüz D, Karadaş Ö, Bolay H (eds.). Springer, Cham, Switzerland, 2019.

49 Juškys R and Šustickas G: Effectiveness of treatment of occipital neuralgia using the nerve block technique: a prospective analysis of 44 patients. Acta Med Litu 25(2): 53-60, 2018. PMID: 30210238. DOI: $10.6001 /$ actamedica.v25i2.3757

50 van Suijlekom H, Van Zundert J, Narouze S, van Kleef M and Mekhail N: 6. Cervicogenic headache. Pain Pract 10(2): 124130, 2010. PMID: 20415729. DOI: 10.1111/j.1533-2500. 2009.00354.x

51 Shauly O, Gould DJ, Sahai-Srivastava S and Patel KM: Greater occipital nerve block for the treatment of chronic migraine headaches: a systematic review and meta-analysis. Plast Reconstr Surg 144(4): 943-952, 2019. PMID: 31568309. DOI: 10.1097/PRS.0000000000006059

52 Blumenfeld A, Ashkenazi A, Grosberg B, Napchan U, Narouze S, Nett B, DePalma T, Rosenthal B, Tepper S and Lipton RB: Patterns of use of peripheral nerve blocks and trigger point injections among headache practitioners in the USA: Results of the American Headache Society Interventional Procedure Survey (AHS-IPS). Headache 50(6): 937-942, 2010. PMID: 20618812 DOI: $10.1111 / \mathrm{j} .1526-4610.2010 .01676 . x$

53 Palamar D, Uluduz D, Saip S, Erden G, Unalan H and Akarirmak U: Ultrasound-guided greater occipital nerve block: an efficient technique in chronic refractory migraine without aura? Pain Physician 18(2): 153-162, 2015. PMID: 25794201.

54 Gerbershagen HJ, Rothaug J, Kalkman CJ and Meissner W: Determination of moderate-to-severe postoperative pain on the numeric rating scale: a cut-off point analysis applying four different methods. Br J Anaesth 107(4): 619-626, 2011. PMID: 21724620. DOI: $10.1093 /$ bja/aer 195
55 van Oosterhout WP, van der Plas AA, van Zwet EW, Zielman R, Ferrari MD and Terwindt GM: Postdural puncture headache in migraineurs and nonheadache subjects: a prospective study. Neurology 80(10): 941-948, 2013. PMID: 23390176. DOI: 10.1212/WNL.0b013e3182840bf6

56 Wang YF, Fuh JL, Lirng JF, Chen SP, Hseu SS, Wu JC and Wang SJ: Cerebrospinal fluid leakage and headache after lumbar puncture: a prospective non-invasive imaging study. Brain 138(Pt 6): 1492-1498, 2015. PMID: 25688077. DOI: 10.1093/ brain/awv016

57 Raskin NH: Lumbar puncture headache: a review. Headache 30(4): 197-200, 1990. PMID: 2186014. DOI: 10.1111/j.15264610.1990.hed3004197.x

58 Urits I, Cai V, Aner M, Simopoulos T, Orhurhu V, Nagda J, Viswanath O, Kaye AD, Hess PE and Gill J: Post dural puncture headache, managed with epidural blood patch, is associated with subsequent chronic low back pain in patients: a pilot study. Curr Pain Headache Rep 24(1): 1, 2020. PMID: 31916041. DOI: 10.1007/s11916-020-0834-5

59 Sansone P, Pace MC, Passavanti MB, Pota V, Colella U and Aurilio C: Epidemiology and incidence of acute and chronic Post-Surgical pain. Ann Ital Chir 86(4): 285-292, 2015. PMID: 26343897.

60 Turnbull DK and Shepherd DB: Post-dural puncture headache: pathogenesis, prevention and treatment. Br J Anaesth 91(5): 718729, 2003. PMID: 14570796. DOI: $10.1093 / \mathrm{bja} / \mathrm{aeg} 231$

61 Chambers D, Rodgers M and Woolacott N: Not only randomized controlled trials, but also case series should be considered in systematic reviews of rapidly developing technologies. J Clin Epidemiol 62(12): 1253-1260.e4, 2009. PMID: 19349144. DOI: 10.1016/j.jclinepi.2008.12.010

Received June 19, 2021

Revised July 16, 2021

Accepted August 11, 2021 